\title{
Current Applications for Nuclear Medicine Imaging in Pulmonary Disease
}

\author{
Joanna E. Kusmirek ${ }^{1}$ (D) Josiah D. Magnusson ${ }^{1} \cdot$ Scott B. Perlman ${ }^{1}$ \\ Published online: 22 July 2020 \\ (C) Springer Science+Business Media, LLC, part of Springer Nature 2020
}

\begin{abstract}
Purpose of Review The main goal of the article is to familiarize the reader with commonly and uncommonly used nuclear medicine procedures that can significantly contribute to improved patient care. The article presents examples of specific modality utilization in the chest including assessment of lung ventilation and perfusion, imaging options for broad range of infectious and inflammatory processes, and selected aspects of oncologic imaging. In addition, rapidly developing new techniques utilizing molecular imaging are discussed.

Recent Findings The article describes nuclear medicine imaging modalities including gamma camera, SPECT, PET, and hybrid imaging (SPECT/CT, PET/CT, and PET/MR) in the context of established and emerging clinical applications. Areas of potential future development in nuclear medicine are discussed with emphasis on molecular imaging and implementation of new targeted tracers used in diagnostics and therapeutics (theranostics).

Summary Nuclear medicine and molecular imaging provide many unique and novel options for the diagnosis and treatment of pulmonary diseases. This article reviews current applications for nuclear medicine and molecular imaging and selected future applications for radiopharmaceuticals and targeted molecular imaging techniques.
\end{abstract}

Keywords Lung scintigraphy $\cdot$ VQ scan $\cdot$ SPECT/CT in lungs $\cdot$ PET/CT in lungs $\cdot$ PET/MR in lungs $\cdot$ Chest infection imaging

\section{Introduction}

Imaging plays an important role in lung diseases and is often complimentary to clinical assessment and testing. As opposed to traditional radiography or computed tomography (CT) which provides a static picture at a point in time, nuclear medicine has the ability to visualize dynamic processes over time. Importantly, this modality provides not only morphologic but also pathophysiologic information. This is very important in the lungs, where different diseases may have the same appearance on CT and more specific tests would be valuable. Additionally, molecular imaging techniques can target and track cells, molecules, or antigens over time, demonstrating

This article is part of the Topical Collection on Pulmonary Radiology

Joanna E. Kusmirek

jkusmirek@uwhealth.org

1 Radiology Department, Section of Nuclear Medicine and Molecular Imaging, Madison School of Medicine and Public Health, University of Wisconsin, 600 Highland Ave, Madison, WI 53792, USA dynamic cellular processes, for example, immune activation and response.

Traditional nuclear medicine involves capturing gamma rays on a 2-D planar gamma camera. Addition of SPECT (single-photon emission computed tomography) results in improved sensitivity and accuracy. Acquisition of both SPECT and $\mathrm{CT}$ further improves accuracy and provides anatomic reference. PET (positron emission tomography) is now routinely acquired with CT (PET/CT), and more recently, PET/MR has become more available. The steady march of PET imaging utilization has proven invaluable in numerous oncologic and non-oncologic diseases.

This article will focus on indications for nuclear medicine and molecular imaging in pulmonary diseases, which can be practically used by a pulmonologist. Selected newer techniques and future directions will be briefly discussed.

\section{Imaging Modalities}

Classic nuclear medicine imaging includes planar imaging, most often static; however, continuous (cine) imaging can 
make an important contribution for specific indications, e.g., flow in lymphatics. The classic design of gamma camera imaging involves detection of gamma radiation emitted by the source (radiotracer in the patient) using a single or multiple $\mathrm{NaI}(\mathrm{Tl})$ crystals. SPECT (single-photon emission computed tomography) employs a gamma camera or multiple gamma cameras that rotate around the patient acquiring multiple 2-D images (projections). Subsequently, a tomographic reconstruction algorithm is used to create a 3-D data set. Addition of SPECT to planar images helps to localize the abnormal uptake, improves diagnostic accuracy, and assessment of the disease extent [1, 2]. However, despite this improvement, SPECT does not provide the exact location. CT can be obtained for attenuation correction and anatomical localization resulting in a hybrid imaging: SPECT/CT, which further improves detection of abnormal radiotracer accumulation [3]. Moreover, SPECT/CT improves reader confidence compared with planar imaging [4]. SPECT/CT is superior compared with planar scintigraphy or SPECT alone with multiple established indications and emerging new applications [5, 6]. Importantly, the CT portion of the exam is typically performed as low dose with limited diagnostic qualities to assure a very low radiation exposure. The effective doses from CT portion of SPECT/CT exam were reported as $0.6-2.6 \mathrm{mSv}$ depending of body area imaged [7-9]. For comparison, the average yearly background radiation dose in the USA is $3.1 \mathrm{mSv}$ and the average dose from chest $\mathrm{CT}$ is $7 \mathrm{mSv}$ [10].

Molecular imaging combines anatomic and molecular information by employing SPECT, PET, MRI, ultrasound, and optical imaging in combination with specific imaging probes (Table 1). The labeled probes are specific for a target at a molecular level allowing for investigation of a specific cellular pathophysiologic process. Current clinical molecular imaging implements SPECT and PET. SPECT allows simultaneous imaging of multiple different molecular probes with different radiotracers; however, it has lower resolution compared with PET [11]. Newer PET techniques regarding simultaneous imaging of different radiopharmaceuticals are under investigation; however, further research is needed [12]. Additional modalities have been explored in ongoing preclinical research, including contrast-enhanced molecular ultrasound (US) with microbubbles and optical imaging with fluorescent probes. Overall, molecular imaging can provide highly specific information and opens pathways to personalized medicine and therapeutic diagnostics (theranostics).

\section{What Can Be New about the VQ Scan?}

Nuclear medicine planar ventilation and perfusion (VQ) scans have served for decades as a foundational pillar of clinical nuclear medicine assessment of suspected pulmonary embolism (PE). Radiolabeled macroaggregated albumin (MAA) is used for the perfusion portion while a variety of inhaled radiopharmaceuticals can be used for ventilation imaging, commonly ${ }^{99 \mathrm{~m}}$ Tc-DTPA (diethylenetriaminepentaacetic acid), ${ }^{133}$ Xenon, and Technegas (gas-like ultra-fine technetium-labeled carbon), widely used in Europe. The traditional VQ scan was obtained as 2-D planar images in several planes. Currently, 3-D SPECT or SPECT/CT imaging is often used with improved image quality and accuracy [13]. Traditional interpretation of VQ scan implemented probability assessment based on the PIOPED [14] clinical trial, and the results were reported as either high, intermediate, low, very low, or normal probability. These categories were never well accepted in the clinical community and were at times not helpful in the management of patients with possible pulmonary embolism. There were subsequently several articles attempting to simplify the interpretation of the VQ scan, and today, many centers report the findings the same way as for other modalities: as positive, negative, or indeterminate. Some advocate using SPECT/CT VQ imaging as the most accurate method of pulmonary embolism evaluation, as the CT improves the specificity while maintaining an excellent sensitivity [15]. Modern day SPECT/ $\mathrm{CT}$ systems can produce a reasonable quality $\mathrm{CT}$ at a very low radiation dose, and the $\mathrm{CT}$ can help determine if a perfusion defect is due to something other than PE, such as pneumonia.

VQ scan is the preferred imaging modality in chronic thromboembolic pulmonary embolism (CTEPH), for both diagnosis and monitoring after therapy (Fig. 1). Perfusion-only imaging can be used for evaluation of right to left shunt, both pulmonary and cardiac, as well as hepatopulmonary syndrome. Perfusion quantitative imaging is commonly used prior to lung volume reduction surgery in COPD and prior to lung transplantation. In addition, this is used for follow-up after cardiac surgery for certain congenital heart diseases and as a monitoring tool after intervention performed on central pulmonary arteries.

VQ SPECT can help to detect early COPD as the scintigraphic findings correlate with spirometric data and extent of emphysema [16]. Technegas ventilation scintigraphy also shows correlation with spirometry and appears promising in the diagnosis and grading of chronic obstructive pulmonary disease (COPD) [17] as well as monitoring treatment response in asthma [18].

Other indications in ventilation or perfusion lung imaging include:

1. Mucociliary clearance $\left({ }^{99 \mathrm{~m}} \mathrm{Tc}\right.$ pertechnetate, ${ }^{99 \mathrm{~m}} \mathrm{Tc}$ sulfur colloid, ${ }^{99 \mathrm{~m}}$ Tc MAA, etc.), e.g., in COPD and asthma.

2. Pulmonary vascular permeability $\left({ }^{99 \mathrm{~m}} \mathrm{Tc}-\mathrm{DTPA}\right)$

3. Pneumoconiosis evaluation with ${ }^{99 \mathrm{~m}} \mathrm{Tc} \mathrm{MAA}$ and ${ }^{67} \mathrm{Ga}$ citrate

4. Bronchopleural fistula detection

5. Bronchiectasis evaluation in children 
6. Drug delivery distribution evaluation with SPECT and PET [19]

7. ${ }^{99 \mathrm{~m}}$ Tc-DTPA aerosol can be used as "screening" in HIV patients if pulmonary infection is suspected and chest radiograph is normal [20]. This is especially useful in pediatric population [21].

\section{Infection/Inflammation Evaluation}

\section{${ }^{67}$ Gallium}

Indications to use ${ }^{67}$ gallium scintigraphy include detection of pulmonary and mediastinal inflammation/infection, especially opportunistic infection in the immunocompromised patient; a negative scan excludes active Pneumocystis jirovecii pneumonia (PJP) and essentially any pulmonary disease [22]. ${ }^{67} \mathrm{Ga}$ can be used for evaluation and followup of lymphocytic or granulomatous inflammatory processes, such as sarcoidosis or tuberculosis [23, 24]. It is sensitive for drug-induced pulmonary toxicity (e.g., bleomycin and amiodarone) [25]. It is preferred over WBC scan in a leukopenic patient. For diagnosing discitis/osteomyelitis, it is preferred over labeled leukocytes. ${ }^{67} \mathrm{Ga}$ scan is negative in adenocarcinoma, squamous cell carcinoma, histiocytosis, and Kaposi sarcoma (which is positive on a thallium scan), but positive in lymphoma. Diffuse ${ }^{67} \mathrm{Ga}$ uptake in lungs is nonspecific, which can be seen in various infectious and inflammatory conditions. Due to long testing time, high frequency of false positive results, relatively high radiation dose, and availability of other modalities (PET/CT), the role of ${ }^{67} \mathrm{Ga}$ scintigraphy in clinical practice has been reduced $[9,18]$.

\section{Labeled Leukocytes in Pulmonary Infections}

Leukocytes can be labeled with ${ }^{111}$ indium-oxine $\left({ }^{111} \mathrm{In}\right)$ or ${ }^{99 \mathrm{~m}} \mathrm{Tc}$-hexamethylpropyleneamine oxime (HMPAO), depending on specific clinical question and anatomic location. The Society of Nuclear Medicine and Molecular Imaging (SNMMI) guidelines state that WBC imaging can be used for detection of suspected sites of acute inflammation/infection in the febrile patient, patients with granulocytosis, and/or positive blood cultures [26, 27]. Per European Association of Nuclear Medicine (EANM) guidelines [28], labeled WBC scintigraphy may be used to detect, localize, and determine the extent of the process in occult lung infection disorders, as well as fever of unknown origin (FUO), endocarditis, postoperative abscesses, infected central venous catheters, or other vascular devices. Disadvantages of scintigraphy with radiolabeled WBC are the requirement of blood handling for radiopharmaceutical preparation, the longer duration of the procedure compared with ${ }^{18} \mathrm{~F}$ 2-deoxyglucose (FDG) PET/CT, and lower spatial resolution. 


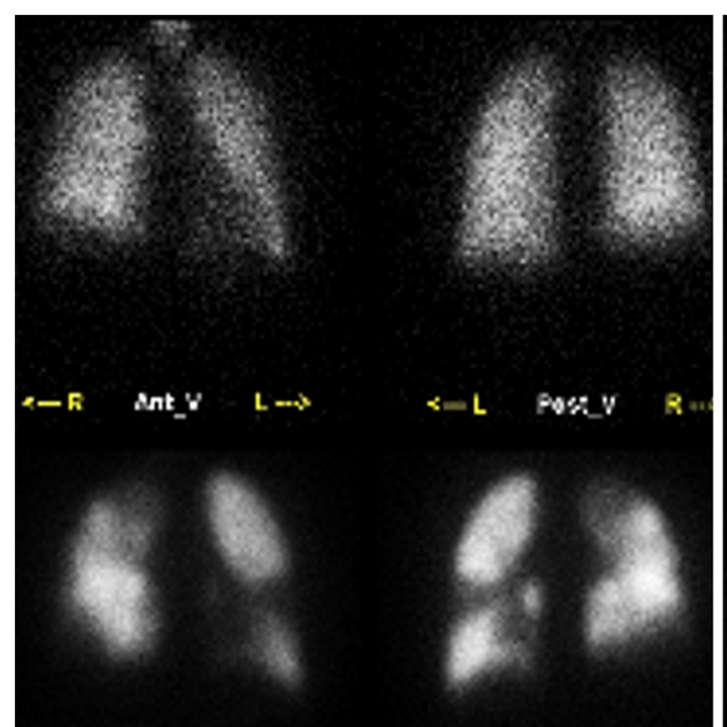

Fig. 1 V/Q scan in chronic thromboembolic pulmonary embolism (CTEPH). A 27-year-old female with chronic dyspnea, recently found to have pulmonary hypertension. V/Q scan: perfusion images in the upper row and perfusion images in the lower row. Left panel shows multiple bilateral mismatched defects. This study was repeated (not

Labeled leukocyte with SPECT/CT imaging is a sensitive test for detecting lung infection, it can be especially beneficial in immunocompromised patients, and a study by Love et al. showed that absence of focal pulmonary activity had a $99 \%$ negative predictive value for excluding pulmonary infection [29]. However, this test is not specific due to possibility of damaged leukocytes accumulation (sequestration) in the lungs, especially on early images. Persistent diffuse uptake in the lung on delayed images may indicate infection or inflammation and is more often seen in heart or renal failure. This may obscure focal lung infections [27]. Atypical lung infections and opportunistic infection, like Pneumocystis jirovecii, as well as sepsis can present with diffuse uptake. Diffuse lung injury of various etiologies can have this appearance, including drug and radiation-related lung injury, ARDS, eosinophilic syndromes, and graft vs host disease. Focal uptake on delayed images can be lobar/ segmental or in non-anatomic distribution. Segmental and lobar uptake suggests pneumonia [30], while non-anatomic distribution of uptake suggests technical errors. ${ }^{99 \mathrm{~m}} \mathrm{Tc}-\mathrm{HMPAO}$ and ${ }^{111} \mathrm{In}$ oxine label predominantly neutrophils, however, due to affinity to eosinophils, false positive results can occur in disorders with eosinophilic infiltration [31]. Labeled neutrophils can be used to quantify lung neutrophil inflammation in COPD in order to evaluate the efficacy of therapy [32].

\section{Infection/Inflammation Indications in Nuclear Medicine}

\section{Fever of Unknown Origin}

Despite multiple available diagnostic tests, FUO still remains challenging. Both labeled WBC and FDG PET can be used in

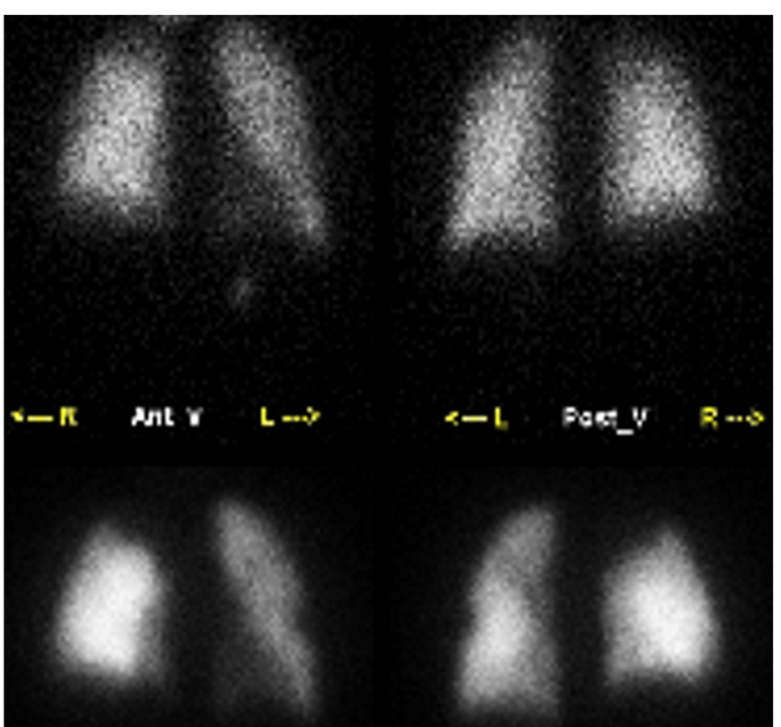

shown) and the defects were unchanged. Findings were consistent with diagnosis of CTEPH. Right panel obtained after embolectomy shows significantly improved perfusion with resolved or decreased perfusion defects

FUO [33, 34]. Some authors favor WBC scan over PET/CT as a first study when there is a high pretest probability for infection [35]. However, FDG PET appears superior to other imaging modalities [36, 37].

\section{Sarcoidosis}

FDG PET/CT is commonly used for evaluation of sarcoidosis including diagnosis, monitoring of disease activity, and response to therapy (Fig. 2). FDG PET/CT can be especially useful in radiographic stage IV disease with fibrosis because the presence of metabolic activity indicates active disease potentially responsive to therapy. Additionally, PET/CT may show active parenchymal disease in radiographic stages 0 and 1 [38, 39].

An additional PET radiotracer that can help diagnose sarcoidosis is ${ }^{11} \mathrm{C}$-methionine used in molecular imaging of amino acid metabolism (Table 2). Because of increased metabolism of amino acids in tumor cells, this agent is useful in tumor imaging. In combination with FDG, this tracer can help to better differentiate inflammation from malignancy [40]. Cardiac PET/MR offers the most comprehensive one-step evaluation of heart involvement and at the same time can assess disease activity throughout the body.

\section{Other Indications for PET/CT in Inflammation and Infection}

- Fungal and parasitic infections - disease activity monitoring, e.g., candidiasis, aspergillosis, [41], and echinococcosis $[42,43]$ 
- AIDS-associated opportunistic infections

- Assessment of metabolic activity in tuberculosis lesions

- Cystic fibrosis - disease activity, response to therapy

- Acute lung injury or acute respiratory distress syndrome [44]

\section{PET/CT in Systemic Inflammatory Diseases}

Over recent years, there has been growth in PET utilization in systemic infections and inflammation for diagnosis, assessment of disease activity, and therapy monitoring [45, 46]. FDG PET/CT can be used for diagnosis and follow-up in multiple inflammatory conditions including rheumatoid arthritis (RA) [47], polymyalgia rheumatica [48], IgG4-relate disease, large vessel vasculitis [49], and granulomatosis with polyangiitis, adult-onset Still disease [50, 51], spondyloarthritis, chronic osteomyelitis, and multicentric reticulohistiocytosis [52]. Increased FDG uptake in the tracheobronchial tree is a reliable sign of cartilage involvement in relapsing polychondritis [53]. FDG PET/CT can be used for early diagnosis of RPC and follow-up [54, 55]. New specific PET tracers are being developed, for example, $\alpha 5 \beta 1$-integrin PET appears to be a promising tool for early diagnosis of RA and therapy monitoring [56].

\section{Future Directions and New Indications}

WBC labeling technique is time-consuming and labeling requires handling a patient's blood. Anti-granulocyte monoclonal antibodies have been developed: whole murine $\mathrm{IgG}$ antiNCA-95 antibody and a Fab' fragment anti-NCA-90. Besilesomab induces production of human anti-mouse antibodies (HAMA). Sulesomab does not induce HAMA production and is approved in Europe for peripheral musculoskeletal infections [35].

Anti-microbial peptides (AMPs) have been developing rapidly, labeled with either SPECT or PET radiotracers. ${ }^{99 \mathrm{~m}}$ Tc-labeled antibiotics can be used for specific indications, for example, ${ }^{99 \mathrm{~m}} \mathrm{Tc}$-ciprofloxacin binds to topoisomerase IV and DNA gyrase expressed by proliferating bacteria and can be used in suspected infections caused Gram-positive, Gramnegative, and anaerobic bacteria [57]. Other antibiotics, such as cephalosporins and fluoroquinolones, ${ }^{99 \mathrm{~m}} \mathrm{Tc}$-vancomycin, and other anti-microbial peptides, for example, ${ }^{99 \mathrm{~m}} \mathrm{Tc}$ ubiquicidin (UBI), have been tested in animal and human studies [58, 59]. Recently, new probes have been proposed for the detection of fungal infections, such as ${ }^{99 \mathrm{~m}}$ Tc-fluconazole. ${ }^{99 \mathrm{~m}}$ Tc-ethambutol planar and SPECT/CT scintigraphy has been shown to be useful in tuberculosis with high sensitivity and specificity for detection of pulmonary and extrapulmonary disease [60].

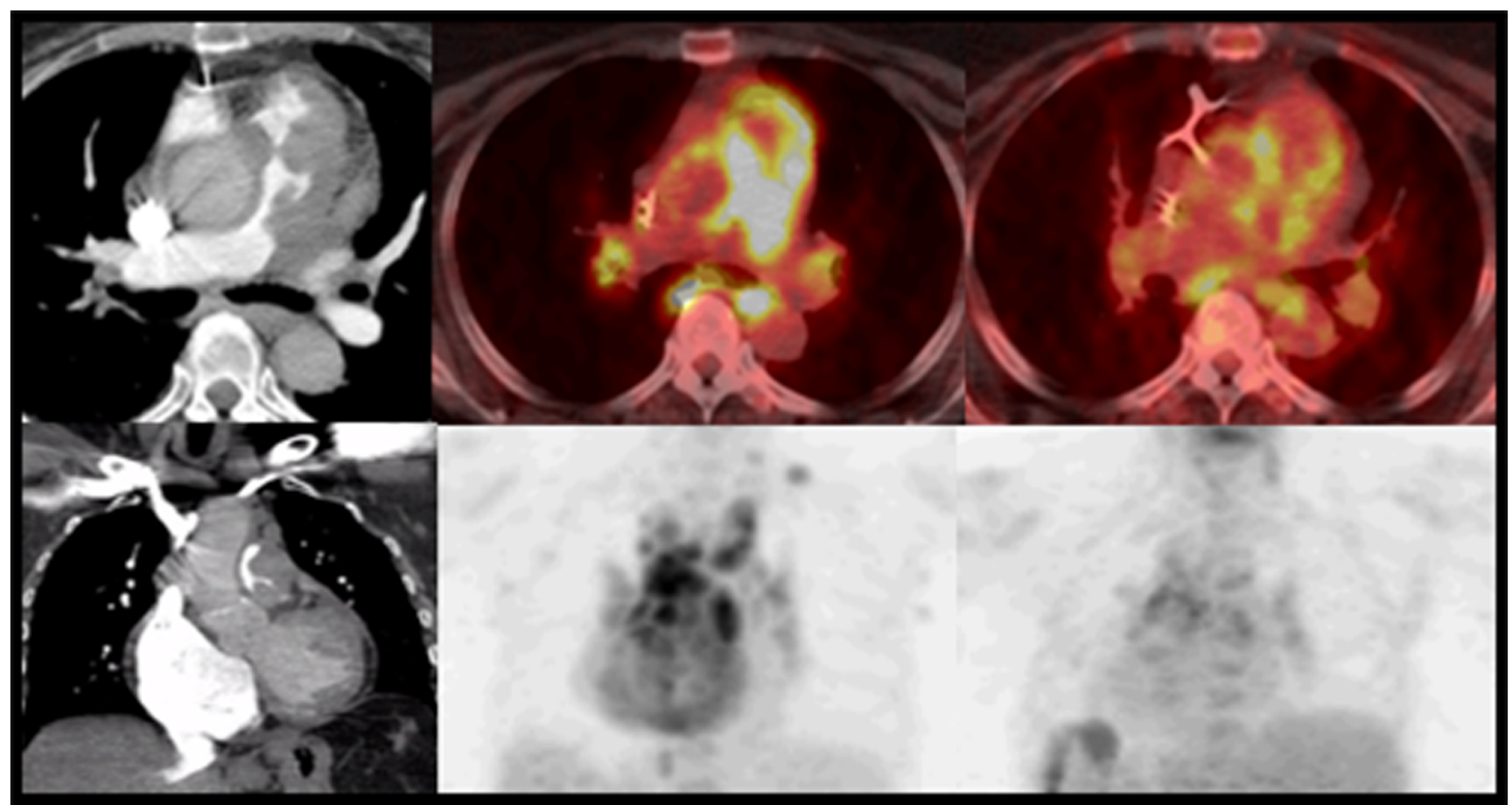

Fig. 2 Evaluation of sarcoidosis with PET/CT. A 54-year-old female underwent CTA PE (left column) showing mass-like lesion in the main pulmonary artery. FDG PET/CT (middle column) was performed per sarcoid protocol which includes high fat and protein, no carbohydrate diet to suppress normal myocardial glucose uptake. The scan shows extensive hypermetabolic activity in this lesion and mediastinal and hilar lymphadenopathy. Biopsy demonstrated angioinvasive sarcoidosis. Follow-up PET/CT (right column) after therapy shows decreasing metabolic activity consistent with response to therapy 


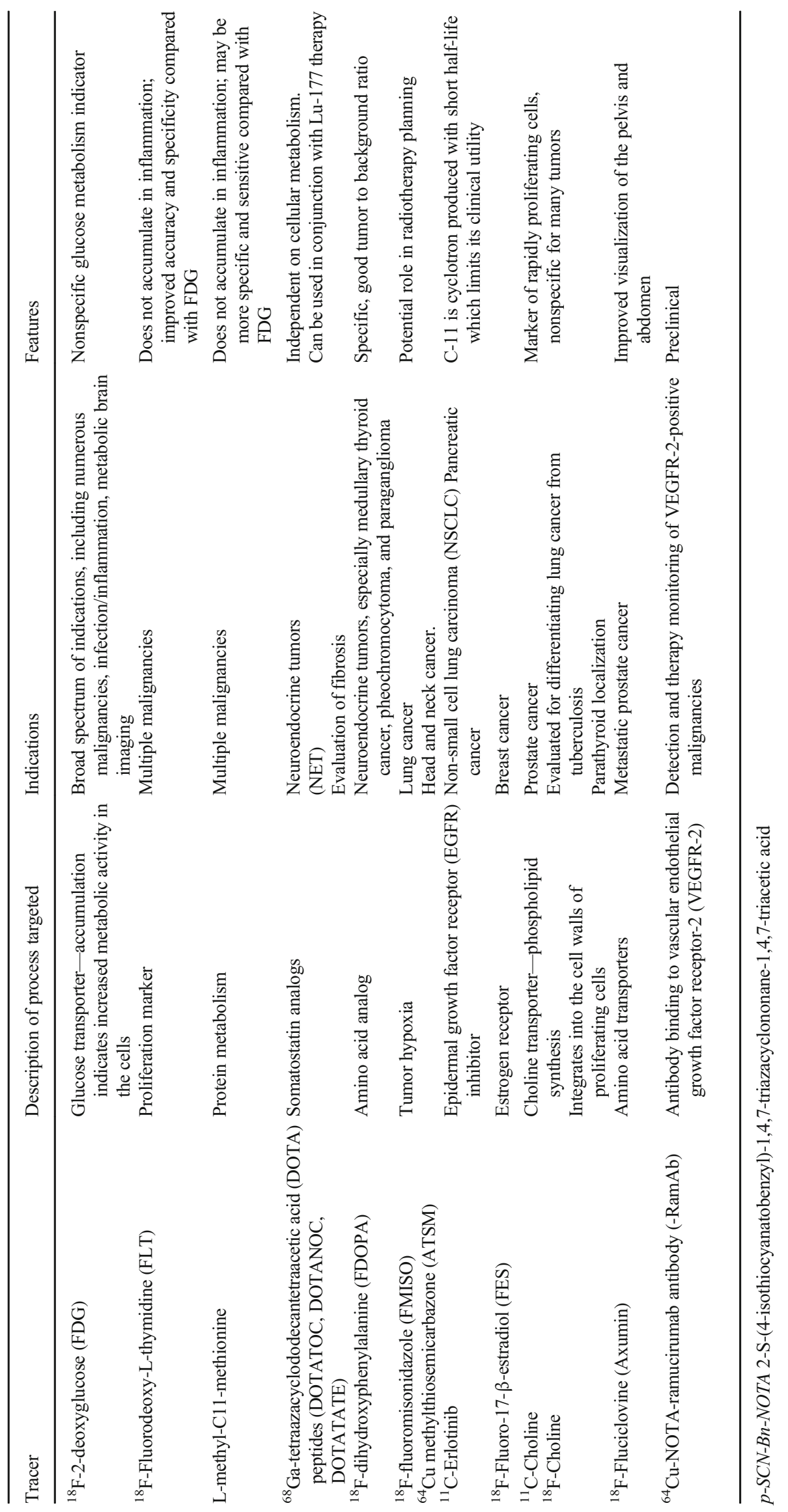


Viral infections could be potentially detected with the help of an emerging radiopharmaceutical for PET/CT studies; for example, ${ }^{18} \mathrm{~F}$-fluoro-5-ethyl-1beta-D-arabinofuranosyluracil $\left({ }^{18}\right.$ F-FEAU) recognizes an enzyme produced by herpes simplex virus [61]. Many new PET radiopharmaceuticals for infection imaging have been tested in preclinical trials with potential to be translated to humans [62].

Multiple molecular probes for fibrosis have been developed, for example, a SPECT/CT agent ${ }^{99 \mathrm{~m}} \mathrm{Tc}-\mathrm{CBP} 1495$ [63], fibroblast targeting somatostatin receptor agents $\left({ }^{111} \mathrm{In}\right.$ octreotide), and numerous ${ }^{68} \mathrm{Ga}$ and ${ }^{64} \mathrm{Cu}$-labeled PET agents $[64,65]$.Currently available techniques can detect established fibrosis; however, there is need to develop tools to improve detection of early disease and monitoring of progression. For example, an ongoing clinical trial evaluates the ability of ${ }^{68} \mathrm{Ga}$-CBP8 probe to detect type I collagen deposition in early IPF and radiation induced fibrosis $[64,66]$.

Molecular imaging techniques for ischemia-reperfusion injury are being investigated primarily for evaluation of primary graft dysfunction in lung transplant. Dimastromatteo has reported promising results using ${ }^{99 \mathrm{~m}}$ Tc-cFLFLF SPECT imaging in a murine model [11].

Matrix metalloproteases (MMPs) secreted by inflammatory cells, predominantly macrophages, have been investigated in asthma and chronic obstructive pulmonary disease (COPD). PET and SPECT tracers have been developed aiming for early detection and monitoring of disease activity [17].

\section{Oncologic Indications}

\section{$\mathrm{PET} / \mathrm{CT}$}

The traditional PET radiotracer is a glucose analog ${ }^{18} \mathrm{~F}-2$ deoxyglucose, which is the most used radiopharmaceutical to date. FDG PET/CT is useful for imaging of inflammation/ infection as described above. However, the most common indications for PET/CT chest imaging are the evaluation of a single pulmonary nodule and lung cancer staging. This modality has an established role in lung cancer staging, radiation therapy planning, treatment monitoring, and prognostication. For pulmonary nodules, most physicians are aware of false positive findings on FDG PET in infection and inflammatory processes. However, false negative results occur as well, especially for small nodules $(<8 \mathrm{~mm})$ located in the lower lobes (motion artifact) and ground glass nodules. Additionally, growing nodules can be falsely negative on PET, and for these nodules, further follow-up and/or biopsy is warranted. Development of many new PET radiotracers based on molecular imaging allows for further growth and expansion of this modality. These can be nonspecific, targeting intracellular processes associated with neoplasms (hypoxia, proliferation, angiogenesis, apoptosis, etc.) (Table 2), or highly specific, showing affinity only to a selected antigen on healthy or malignant cells $[67,68]$. For example, deoxy$3^{\prime}{ }^{18}$ fluorothymidine $\left({ }^{18} \mathrm{~F}-\mathrm{FLT}\right)$ is a marker of proliferation and does not accumulate in inflammatory lesions $[67,68]$. Zannetti et al. evaluated ${ }^{18} \mathrm{~F}$-FLT PET/CT in order to improve selection of patients with lung cancer who may benefit from specific targeted therapies [69]. The second group of newer tracers includes radiolabeled antibodies, peptides, or other ligands. These tracers have been shown to be highly specific and useful in both diagnosis and treatment response assessment. For example, endothelial growth factor (EGF) receptor targeting drugs can be radiolabeled and potentially used as a pretreatment imaging to predict response to therapy [70]. Multiple ongoing trials explore PET role in predicting response to immunotherapy using radiolabeled antibodies, antibody fragments, and small molecules (e.g., ${ }^{89} \mathrm{Zr}$-nivolumab in patients with non-small cell lung cancer) [71, 72]. Overall, $\mathrm{PET} / \mathrm{CT}$ is playing an important role in development of precision medicine leading to improved therapies and patient outcomes [73].

\section{Neuroendocrine Tumor Imaging}

Pulmonary carcinoid (PC) accounts for more than $25 \%$ of all carcinoid tumors in the body and 1-2\% of all pulmonary neoplasms [74]. They have somatostatin receptors (SSTR) and can be identified on somatostatin analog octreotide scans radiolabeled with indium $\left({ }^{111} \mathrm{In}\right)$ [75]. Carcinoid tumors with malignant potential show increased FDG uptake on PET/CT due to high metabolic activity. However, utility of FDG PET/ $\mathrm{CT}$ for staging of pulmonary carcinoid remains controversial [76]. Functional PET/CT imaging targeting SSTR can utilize 68-gallium-radiolabelled tetraazacyclododecantetraacetic acid (DOTA) peptides (DOTATOC, DOTANOC, DOTATATE) and ${ }^{18} \mathrm{~F}$-dihydroxyphenylalanine (FDOPA). According to the data from 352 patients [77], Ga-DOTA-peptide was superior to FDG $(90.0 \%$ vs $71.0 \%)$ in detection of PC. Management of PC depends on tumor grade and SSTR expression. High uptake of radiolabeled somatostatin analogs (SSAs) and low uptake of ${ }^{18} \mathrm{~F}$-FDG are considered the functional imaging pattern of low-grade well-differentiated tumors. Conversely, low uptake of radiolabeled SSAs (or ${ }^{18} \mathrm{~F}$ FDOPA) and high uptake of FDG are representative of highgrade poorly differentiated tumors [78]. Studies suggest that low or no FDG uptake on PET/CT favors more conservative management [79].

\section{PET/MR}

MRI provides excellent tissue characterization without using ionizing radiation, but imaging of the lungs is challenging due 
to low proton density. The development of hybrid PET/MRI provides an opportunity to provide the most comprehensive assessment of malignancy combining functional and anatomic information [80] (Fig. 3). ${ }^{19} \mathrm{~F}$ MR may also allow the measurement of lung inflammation. Emulsified perfluorocarbons are phagocytized by monocytes and macrophages and can be easily detected by using fluorine ${ }^{19} \mathrm{~F}$ MRI. This technique can be potentially used for lung imaging and drug development [81].

The detection rate of MR for nodules less than $1 \mathrm{~cm}$ in diameter is lower compared with diagnostic CT. However, Raad et al. showed that most small non-FDG avid lung nodules missed on PET/MRI either resolved or remained stable on follow-up, suggestive of benignity [82]. Specific sequences allow better visualization of lung parenchyma including pulmonary nodules and consolidations [83]. MRI with diffusionweighted imaging (DWI) may be considered an alternative to 18F-FDG PET/CT in characterization of pulmonary nodules and NSCLC staging and treatment follow-up [84]. The study by Schaarschmidt et al. evaluated staging differences between $\mathrm{PET} / \mathrm{MR}$ and PET/CT in 77 patients with non-small cell lung cancer (NSCLC) and demonstrated that both modalities lead to comparable therapeutic decisions [85].

\section{Pleura}

FDG PET/CT can be used in differentiating between malignant and benign pleural lesions. The meta-analysis of $11 \mathrm{se}-$ lected studies by Treglia et al. demonstrated sensitivity of $95 \%$ and specificity of $82 \%$ [86]. The ability to distinguish malignant from benign pleural effusion is limited [87] with reported sensitivity of $81 \%$ and specificity of $74 \%$ [88]. However, the study by Yildirim et al. reported high sensitivity, specificity, and accuracy $(88.2 \%, 92.9 \%$, and $90.3 \%$, respectively) for differentiation of malignant mesothelioma from asbestosrelated benign pleural disease in a group of 31 patients [89] evaluated by PET/CT. Similarly, Sun et al. reported high sensitivity of $93 \%$ for FDG PET/CT in differentiating malignant from benign pleural effusion [90].The recent TARGET trial explores the potential role of FDG PET/CT to target areas of high uptake when performing a CT-guided biopsy [91].

In patients with pleural effusion who are on peritoneal dialysis or who have liver disease (hepatic hydrothorax), ${ }^{99 \mathrm{~m}} \mathrm{Tc}$ MAA or ${ }^{99 \mathrm{~m}} \mathrm{Tc}$ sulfur colloid can be used for assessment because they are not absorbed systemically. If there is communication between the peritoneum and pleural space, lung uptake is usually seen in $10 \mathrm{~min}$. Similarly, patency of drainage

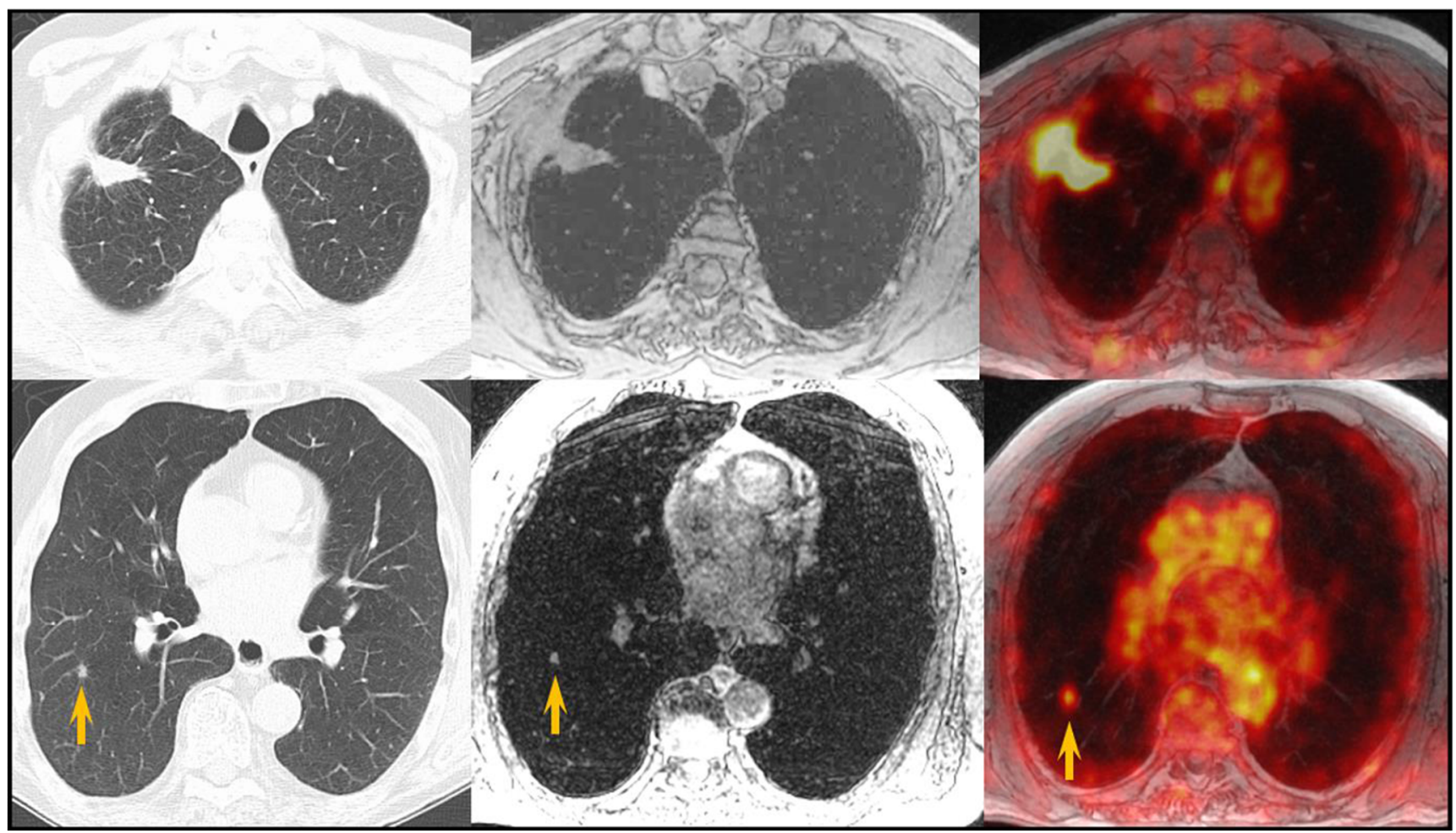

Fig. 3 PET/MR findings in a patient with lung cancer. A 61-year-old male with right upper lobe cancer treated with radiation therapy. Highresolution CT images (left column) demonstrated decreased size of the mass and a new 6-mm nodule in the right lower lobe. FDG PET/MR was obtained. The MR portion (middle column) remonstrated the RUL mass and RLL nodule. Fused PET and MR images show that the mass was intensely hypermetabolic suspicious for residual/recurrent disease and the nodule was mild to moderately hypermetabolic suspicious for second primary vs metastatic lung cancer 

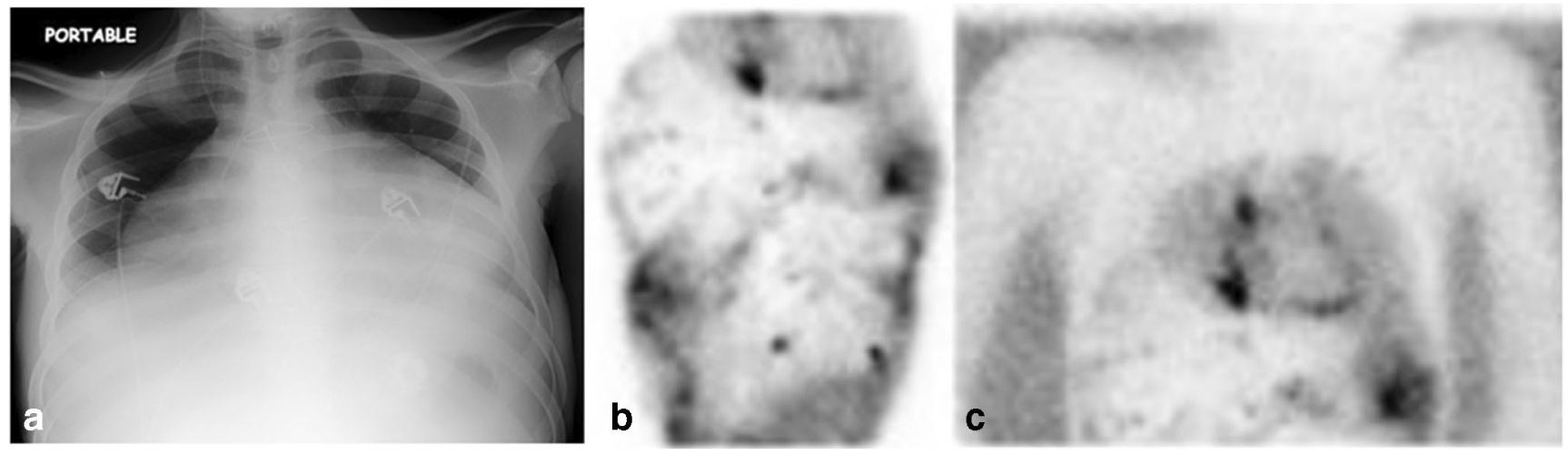

Fig. 4 Hepatic hydrothorax and shunt evaluation. In patients with pleural effusion who are on peritoneal dialysis or who have liver disease (hepatic hydrothorax), ${ }^{99 \mathrm{~m}} \mathrm{Tc}$ MAA or ${ }^{99 \mathrm{~m}} \mathrm{Tc}$ sulfur colloid can be used for shunt assessment. If there is communication between the peritoneum and pleural space, lung uptake is usually seen in $10 \mathrm{~min}$. Similarly, patency of drainage and shunt catheters can be assessed, including pleurovenous and peritoneovenous shunts. The images demonstrate evaluation in a 16-

and shunt catheters can be assessed, including pleurovenous and peritoneovenous shunts (Fig. 4).

\section{Extrapulmonary Indications in the Chest}

\section{Vascular Infections}

For infectious endocarditis (IE), the labeled leukocyte scan is most valuable in patients with "possible IE" by Duke criteria, when there is a high level of clinical suspicion but negative or indeterminate echocardiographic findings [92, 93]. Radiolabeled WBC SPECT/CT is more specific for the detection of prosthetic valve IE and infectious foci than FDG PET/ CT [94]. FDG PET/CT has value in detection of septic emboli and extra-cardiac infection source [95].

Mycotic aneurysms can be difficult to differentiate on CT or MR from non-infectious aneurysms and ${ }^{111} \mathrm{In}$ WBC or FDG PET/CT scan can be useful in establishing the diagnosis as well as detecting additional sites of the disease.

Vascular graft imaging with labeled WBCs demonstrates high sensitivity and can be used for detecting, localizing, and defining the extent of infection $[96,97]$. However, evaluation in the early postoperative period is limited $[98,99]$. A positive scan early in the postoperative period can be secondary to normal endothelialization of the graft or infection.

Cardiovascular implantable electronic device (CIED) infection can be assessed with WBC scintigraphy, especially if SPECT/CT technique is utilized [100]. Based on available data, both WBC SPECT/CT and FDG PET/CT studies may play a role in the diagnosis of CIED infection; however, they are not incorporated in the 2015 European Society of Cardiology guidelines [101-103]. year-old male with Budd-Chiari syndrome, refractory ascites, and Denver (mesoatrial) shunt who presents with dyspnea. Image A: frontal chest radiograph showing a large pericardial effusion. A pericardial drain was radiotracer in the peritoneal cavity but no progression into the lungs. Tracer accumulation around the heart indicating shunt communication with the pericardial space

\section{Aspiration}

${ }^{99 \mathrm{~m}} \mathrm{Tc}-\mathrm{DTPA}$ or ${ }^{99 \mathrm{~m}} \mathrm{Tc}$ sulfur colloid salivagram can be used to help in the diagnosis of aspiration and is more sensitive than the fluoroscopic techniques. Videofluoroscopic evaluation of swallowing (VFES) may fail to identify aspiration in up to $30 \%$ of patients, especially saliva aspiration [104-106].

\section{Extramedullary Hematopoiesis}

${ }^{99 \mathrm{~m}} \mathrm{Tc}$ sulfur colloid can be used to differentiate this entity from other paraspinal lesions. It may be especially useful in pulmonary extramedullary hematopoiesis which can involve the pleural space, pulmonary parenchyma, and rarely the pulmonary artery [107].

\section{Splenosis}

Classic indications for scintigraphic imaging include suspected thoracic splenosis, which may be found after splenic injury. In $75 \%$ of patient, splenosis presents as multiple pleura-based nodules; in $25 \%$ of patients, a solitary nodule is present. The average time from the event to diagnosis is 21 years [108]. Diagnosis can be established with ${ }^{99 \mathrm{~m}} \mathrm{Tc}$ sulfur colloid scintigraphy, ${ }^{99 \mathrm{~m}} \mathrm{Tc}$ heat-damaged erythrocytes, or ${ }^{111}$ In-labeled platelets (Fig. 5).

\section{Thrombus Evaluation}

Molecular imaging is used to investigate venous thrombosis [109] including determination of thrombus activity and acuity which may play an important role in patient management. ${ }^{99 \mathrm{~m}} \mathrm{Tc}$ apcitide binds to glycoprotein receptor GPIIb-IIIa on the membrane of activated platelets. This can identify acute subsequently placed. Images B and C: ${ }^{99 \mathrm{~m}} \mathrm{Tc}$ shunt scintigraphy showing 
Fig. 5 Evaluation of splenosis. An incidental pleura-based nodule was identified on contrastenhanced chest CT (arrowhead). Note that the spleen is absent (circle). ${ }^{99 \mathrm{~m}}$ Tc-labeled sulfur colloid scintigraphy anterior (upper) and posterior (lower) views show tracer accumulation withing the nodule (arrows) consistent with splenic tissue
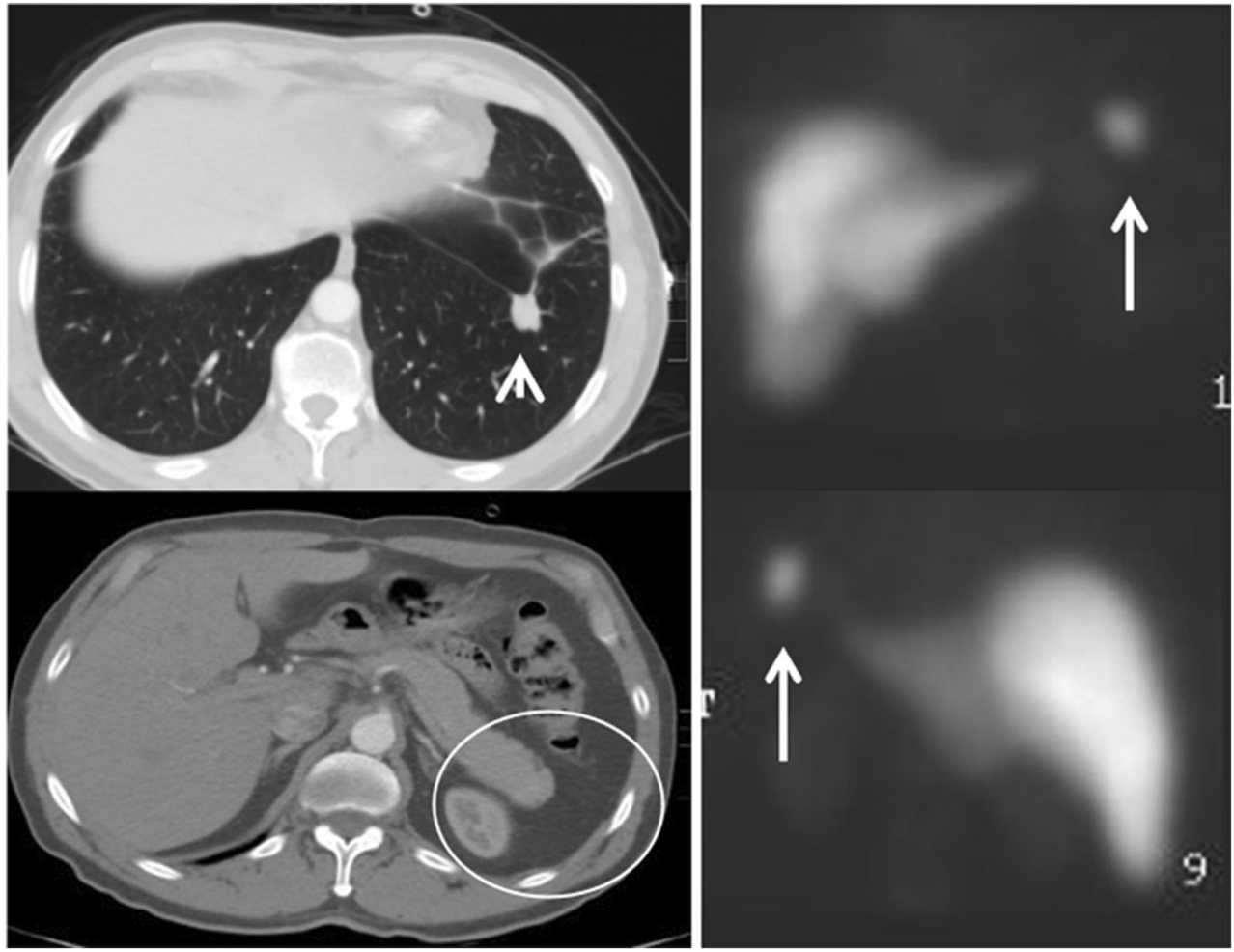

deep venous thrombosis (DVT) $[110,111]$. This test has been FDA approved, but is not widely used. An additional compound ${ }^{99 \mathrm{~m}}$ Tc-DI-DD3B6/22-80B3 $\left({ }^{99 \mathrm{~m}}\right.$ Tc-DI-80B3 Fab'), a humanized monoclonal $\mathrm{Fab}^{\prime}$ fragment that binds to $\mathrm{D}$-dimer, showed good safety profile and promising accuracy in phase I and II trials $[112,113]$. PET tracers are also under active investigation, for example, ${ }^{64} \mathrm{Cu}$-DOTA fibrin-targeted probes which have been tested in animal models [114].

\section{Theranostics}

Theranostics, a combination of therapeutic and diagnostic approaches, is one of the most exciting areas in molecular imaging. This refers to the idea of targeted molecular imaging using radionuclide-labeled molecules not only for imaging but also for therapy delivery. Radionuclides with optimal decay characteristics can serve as delivery system for targeted radiation therapy. Radiation has proven to be a very useful treatment option for different cancers, but it is limited in that its source is external and the treatment affects all the tissue in the radiation field. With theranostics, the source of radiation is internalized targeting specific malignant cells throughout the body including micro-metastatic disease. Locally delivered radiation damages the DNA triggering apoptosis in the targeted cells. Pretreatment scans and therapy can use the same "carrier"; however, a different radionuclide attached to the carrier can be used for the imaging and therapy. Certain theranostic radiopharmaceutical pairs are already in clinical use; for example, ${ }^{68} \mathrm{Ga}$-DOTATATE $/{ }^{177} \mathrm{Lu}$-DOTATATE represents the theranostic pair of labeled somatostatin analogs for neuroendocrine cancers where the ${ }^{68} \mathrm{Ga}$-DOTATATE is used for imaging and the ${ }^{177}$ Lu-DOTATATE for therapy if the tumors are positive on the ${ }^{68} \mathrm{Ga}$-DOTATATE imaging which confirms they have the somatostatin receptor-2 (SSTR-2).

Additional radiolabeled antibodies appear promising in preclinical and clinical trials. This includes ${ }^{177} \mathrm{Lu}$-lilotomab, a CD37 antibody for the treatment of B cell lymphomas and antibodies against fibroblast activation protein [115]. In summary, theranostics has the potential to become personalized precision-based cancer therapeutics.

Heat shock proteins, also known as stress proteins, investigated for oncologic applications, appear to play a role in pathogenesis of pulmonary fibrosis [116]. These are being investigated as potential biomarkers and therapeutic targets in idiopathic pulmonary fibrosis [117].

\section{Conclusions}

Nuclear medicine offers many diverse applications for chest imaging. Many routine indications are utilized in daily practice with selected techniques used as problem-solving tools. Molecular imaging is a rapidly developing field with extensive ongoing research and expanding indications. These newer imaging techniques have a substantial impact on the 
patient management and outcome. In addition, theranostics expands the therapeutic role of nuclear medicine. Nuclear medicine and molecular imaging significantly contribute to the development of targeted therapies and precision medicine leading to improved patient care.

\section{Compliance with Ethical Standards}

Conflict of Interest The authors declare that they have no conflict of interest.

Human and Animal Rights and Informed Consent This article does not contain any studies with human or animal subjects performed by any of the authors.

\section{References}

1. Eberl S, Chan HK, Daviskas E. SPECT imaging for radioaerosol deposition and clearance studies. J Aerosol Med. 2006;19(1):820.

2. Hutton BF. The origins of SPECT and SPECT/CT. Eur J Nucl Med Mol Imaging. 2014;41(Suppl 1):S3-16.

3. Jacene H, Goetze S, Patel H, Wahl R, Ziessman H. Advantages of hybrid SPECT/CT vs SPECT alone. The Open Medical Imaging Journal. 2008;2:67-79.

4. Djekidel M, Brown RK, Piert M. Benefits of hybrid SPECT/CT for (111)In-oxine- and Tc-99m-hexamethylpropylene amine oxime-labeled leukocyte imaging. Clin Nucl Med. 2011;36(7): e50-6.

5. Israel O, Pellet O, Biassoni L, De Palma D, Estrada-Lobato E, Gnanasegaran G, et al. Two decades of SPECT/CT - the coming of age of a technology: an updated review of literature evidence. Eur J Nucl Med Mol Imaging. 2019;46(10):1990-2012.

6. Chowdhury FU, Scarsbrook AF. The role of hybrid SPECT-CT in oncology: current and emerging clinical applications. Clin Radiol. 2008;63(3):241-51.

7. Charest M, Asselin C. Effective dose in nuclear medicine studies and SPECT/CT: dosimetry survey across Quebec Province. Journal of nuclear medicine technology. 2018;46(2):107-13.

8. Rausch I, Fuchsel FG, Kuderer C, Hentschel M, Beyer T. Radiation exposure levels of routine SPECT/CT imaging protocols. Eur J Radiol. 2016;85(9):1627-36.

9. Montes C, Tamayo P, Hernandez J, Gomez-Caminero F, García S, Martín C, et al. Estimation of the total effective dose from lowdose $\mathrm{CT}$ scans and radiopharmaceutical administrations delivered to patients undergoing SPECT/CT explorations. Ann Nucl Med. 2013;27(7):610-7.

10. Schauer DA, Linton OW. NCRP report no. 160 , ionizing radiation exposure of the population of the United States, medical exposure - are we doing less with more, and is there a role for health physicists? Health Phys. 2009;97(1):1-5.

11. Dimastromatteo J, Charles EJ, Laubach VE. Molecular imaging of pulmonary diseases. Respir Res. 2018;19(1):17.

12. Kadrmas DJ, Hoffman JM. Methodology for quantitative rapid multi-tracer PET tumor characterizations. Theranostics. 2013;3(10):757-73.

13. Roach PJ, Schembri GP, Bailey DL. V/Q scanning using SPECT and SPECT/CT. Journal of nuclear medicine : official publication, Society of Nuclear Medicine. 2013;54(9):1588-96.
14. Value of the ventilation/perfusion scan in acute pulmonary embolism. Results of the prospective investigation of pulmonary embolism diagnosis (PIOPED). Jama. 1990;263(20):2753-9.

15. Gutte H, Mortensen J, Jensen CV, Johnbeck CB, von der Recke P, Petersen CL, et al. Detection of pulmonary embolism with combined ventilation-perfusion SPECT and low-dose CT: head-tohead comparison with multidetector CT angiography. Journal of nuclear medicine : official publication, Society of Nuclear Medicine. 2009;50(12):1987-92.

16. Jogi J, Ekberg M, Jonson B, Bozovic G, Bajc M. Ventilation/ perfusion SPECT in chronic obstructive pulmonary disease: an evaluation by reference to symptoms, spirometric lung function and emphysema, as assessed with HRCT. Eur J Nucl Med Mol Imaging. 2011;38(7):1344-52.

17. Myc LA, Shim YM, Laubach VE, Dimastromatteo J. Role of medical and molecular imaging in COPD. Clin Transl Med. 2019;8(1):12.

18. Giraudo C, Evangelista L, Fraia AS, Lupi A, Quaia E, Cecchin D, et al. Molecular imaging of pulmonary inflammation and infection. Int J Mol Sci. 2020;21(3):894.

19. Dolovich M, Labiris R. Imaging drug delivery and drug responses in the lung. Proc Am Thorac Soc. 2004;1(4):329-37.

20. Robinson DS, Cunningham DA, Dave S, Fleming J, Mitchell DM. Diagnostic value of lung clearance of $99 \mathrm{mTc}$ DTPA compared with other non-invasive investigations in Pneumocystis carinii pneumonia in AIDS. Thorax. 1991;46(10):722-6.

21. Deep A, Bhure SU, Bhure UN, Joshi SM, Bhatt BM, Desai SA, et al. Efficacy of $99 \mathrm{mTc}-\mathrm{DTPA}$ lung clearance test in the diagnosis of PCP in HIV-positive patients. J Trop Pediatr. 2009;55(2): 97-102.

22. Palestro CJ, Torres MA. Radionuclide imaging of nonosseous infection. The quarterly journal of nuclear medicine : official publication of the Italian Association of Nuclear Medicine (AIMN) [and] the International Association of Radiopharmacology (IAR). 1999;43(1):46-60.

23. Goldfarb CR, Colp C, Ongseng F, Finestone H, Havas J. Gallium scanning in the 'new' tuberculosis. Clin Nucl Med. 1997;22(7): $470-4$.

24. Sathekge M, Maes A, D'Asseler Y, Vorster M, Van de Wiele C. Nuclear medicine imaging in tuberculosis using commercially available radiopharmaceuticals. Nucl Med Commun. 2012;33(6):581-90.

25. Schuster DM, Alazraki N. Gallium and other agents in diseases of the lung. Semin Nucl Med. 2002;32(3):193-211.

26. Palestro CJ BM, Forstrom LA, Greenspan BS, McAfee JG, Royal HD, Schauwecker DS, Seabold JE, Signore A. . Society of Nuclear Medicine Procedure Guideline for $99 \mathrm{mTc}$-exametazime (HMPAO)-labeled leukocyte scintigraphy for suspected infection/ inflammation. 2004 [https://www.snmmi.org/ClinicalPractice/ content.aspx?ItemNumber=6414\#InfecInflamm].

27. Palestro C, Brown M, Forstrom L, McAfee J, Royal H, Schauwecker D, et al. Society of Nuclear Medicine Procedure Guideline for 99mTc-exametazime (HMPAO)-labeled leukocyte scintigraphy for suspected infection/inflammation. 2004 [https:// www.snmmi.org/ClinicalPractice/content.aspx?ItemNumber= 6414\#InfecInflamm].

28. de Vries EF, Roca M, Jamar F, Israel O, Signore A. Guidelines for the labelling of leucocytes with $(99 \mathrm{~m}) \mathrm{Tc}-\mathrm{HMPAO}$. Inflammation/ Infection Taskgroup of the European Association of Nuclear Medicine. Eur J Nucl Med Mol Imaging. 2010;37(4):842-8.

29. Palestro CJ, Love C, Miller TT. Diagnostic imaging tests and microbial infections. Cell Microbiol. 2007;9(10):2323-33.

30. Love C, Opoku-Agyemang P, Tomas MB, Pugliese PV, Bhargava KK, Palestro CJ. Pulmonary activity on labeled leukocyte images: physiologic, pathologic, and imaging correlation. RadioGraphics. 2002;22(6):1385-93. 
31. Koranda P, Drymlová J, Malý T, Kantor L, Ptácek J, Myslivecek M. Tc-99m exametazime (HMPAO)-labeled leukocyte scintigraphy in premature infants: detection and localization of necrotic enterocolitis and osteomyelitis. Clin Nucl Med. 2011;36(6):e35e6.

32. Tregay N, Begg M, Cahn A, Farahi N, Povey K, Madhavan S, et al. Use of autologous $<$ sup $>99 \mathrm{~m}</$ sup $>$ technetium-labelled neutrophils to quantify lung neutrophil clearance in COPD. Thorax. 2019;74(7):659-66.

33. Gaeta GB, Fusco FM, Nardiello S. Fever of unknown origin: a systematic review of the literature for 1995-2004. Nucl Med Commun. 2006;27(3):205-11.

34. Mulders-Manders C, Simon A, Bleeker-Rovers C. Fever of unknown origin. Clin Med (Lond). 2015;15(3):280-4.

35. Signore A, Jamar F, Israel O, Buscombe J, Martin-Comin J, Lazzeri E. Clinical indications, image acquisition and data interpretation for white blood cells and anti-granulocyte monoclonal antibody scintigraphy: an EANM procedural guideline. Eur J Nucl Med Mol Imaging. 2018;45(10):1816-31.

36. Królicki L. "To be or not to be" for PET in rheumatology. A marriage of love or of convenience? Reumatologia. 2017;55(1): $1-3$.

37. Ergul N, Cermik TF. FDG-PET or PET/CT in fever of unknown origin: the diagnostic role of underlying primary disease. Int J Mol Imaging. 2011;2011:318051.

38. Teirstein AS, Machac J, Almeida O, Lu P, Padilla ML, Iannuzzi MC. Results of 188 whole-body fluorodeoxyglucose positron emission tomography scans in 137 patients with sarcoidosis. Chest. 2007;132(6):1949-53.

39. Keijsers RGM, Grutters JC. In which patients with sarcoidosis is FDG PET/CT indicated? J Clin Med. 2020;9(3):890.

40. Kashefi A, Kuo J, Shelton DK. Molecular imaging in pulmonary diseases. AJR Am J Roentgenol. 2011;197(2):295-307.

41. Franzius C, Biermann M, Hülskamp G, Frosch M, Roth J, Sciuk J, et al. Therapy monitoring in aspergillosis using F-18 FDG positron emission tomography. Clin Nucl Med. 2001;26(3):232-3.

42. Reuter S, Schirrmeister H, Kratzer W, Dreweck C, Reske SN, Kern P. Pericystic metabolic activity in alveolar echinococcosis: assessment and follow-up by positron emission tomography. Clin Infect Dis. 1999;29(5):1157-63.

43. Yibulayin A, Li XH, Qin YD, Jia XY, Zhang QZ, Li YB. Biological characteristics of 18F-FDG PET/CT imaging of cerebral alveolar echinococcosis. Medicine. 2018;97(39):e11801.

44. Becker W, Meller J. The role of nuclear medicine in infection and inflammation. Lancet Infect Dis. 2001;1(5):326-33.

45. Hess S, Alavi A, Basu S. PET-based personalized management of infectious and inflammatory disorders. PET clinics. 2016;11(3): $351-61$.

46. Treglia G. Diagnostic performance of (18)F-FDG PET/CT in infectious and inflammatory diseases according to published metaanalyses. Contrast Media Mol Imaging. 2019;2019:3018349.

47. Kumar NS, Shejul Y, Asopa R, Basu S. Quantitative metabolic volumetric product on (18)fluorine-2fluoro-2-deoxy-D-glucosepositron emission tomography/computed tomography in assessing treatment response to disease-modifying antirheumatic drugs in rheumatoid arthritis: multiparametric analysis integrating American College of Rheumatology/European League against rheumatism criteria. World J Nucl Med. 2017;16(4):293-302.

48. Rehak Z, Sprlakova-Pukova A, Kazda T, Fojtik Z, Vargova L, Nemec P. (18)F-FDG PET/CT in polymyalgia rheumatica-a pictorial review. Br J Radiol. 2017;90(1076):20170198.

49. Grayson PC, Alehashemi S, Bagheri AA, Civelek AC, Cupps TR, Kaplan MJ, et al. (18) F-Fluorodeoxyglucose-positron emission tomography as an imaging biomarker in a prospective, longitudinal cohort of patients with large vessel vasculitis. Arthritis Rheumatol. 2018;70(3):439-49.
50. Yamashita H, Kubota K, Takahashi Y, Minamimoto R, Morooka $\mathrm{M}$, Kaneko $\mathrm{H}$, et al. Clinical value of (1)(8)F-fluorodexoxyglucose positron emission tomography/computed tomography in patients with adult-onset Still's disease: a seven-case series and review of the literature. Mod Rheumatol. 2014;24(4): 645-50.

51. An YS, Suh CH, Jung JY, Cho H, Kim HA. The role of $18 \mathrm{~F}$ fluorodeoxyglucose positron emission tomography in the assessment of disease activity of adult-onset Still's disease. Korean J Intern Med. 2017;32(6):1082-9.

52. Hotta M, Minamimoto R, Kaneko H, Yamashita H. Fluorodeoxyglucose PET/CT of arthritis in rheumatic diseases: a pictorial review. RadioGraphics. 2020;40(1):223-40.

53. Wang J, Li S, Zeng Y, Chen P, Zhang N, Zhong N. (1)(8)F-FDG $\mathrm{PET} / \mathrm{CT}$ is a valuable tool for relapsing polychondritis diagnose and therapeutic response monitoring. Ann Nucl Med. 2014;28(3): 276-84.

54. Yamashita H, Takahashi H, Kubota K, Ueda Y, Ozaki T, Yorifuji $\mathrm{H}$, et al. Utility of fluorodeoxyglucose positron emission tomography/computed tomography for early diagnosis and evaluation of disease activity of relapsing polychondritis: a case series and literature review. Rheumatology (Oxford, England). 2014:53(8):1482-90.

55. Kubota K, Yamashita H, Mimori A. Clinical value of FDG-PET/ $\mathrm{CT}$ for the evaluation of rheumatic diseases: rheumatoid arthritis, polymyalgia Rheumatica, and relapsing polychondritis. Semin Nucl Med. 2017;47(4):408-24.

56. Notni J, Gassert FT, Steiger K, Sommer P, Weichert W, Rummeny EJ, et al. In vivo imaging of early stages of rheumatoid arthritis by alpha5beta1-integrin-targeted positron emission tomography. EJNMMI Res. 2019;9(1):87.

57. Auletta S, Galli F, Lauri C, Martinelli D, Santino I, Signore A. Imaging bacteria with radiolabelled quinolones, cephalosporins and siderophores for imaging infection: a systematic review. Clin Transl Imaging. 2016;4:229-52.

58. Welling MM, Hensbergen AW, Bunschoten A, Velders AH, Roestenberg M, van Leeuwen FWB. An update on radiotracer development for molecular imaging of bacterial infections. Clinical and Translational Imaging. 2019;7(2):105-24.

59. Lawal I, Zeevaart J, Ebenhan T, Ankrah A, Vorster M, Kruger HG, et al. Metabolic imaging of infection. Journal of nuclear medicine : official publication, Society of Nuclear Medicine. 2017;58(11):1727-32.

60. Kartamihardja AHS, Kurniawati Y, Gunawan R. Diagnostic value of $(99 \mathrm{~m}) \mathrm{Tc}$-ethambutol scintigraphy in tuberculosis: compared to microbiological and histopathological tests. Ann Nucl Med. 2018;32(1):60-8.

61. Signore A, Lauri C, Auletta S, Anzola K, Galli F, Casali M, et al. Immuno-imaging to predict treatment response in infection, inflammation and oncology. J Clin Med. 2019;8(5):681.

62. Auletta S, Varani M, Horvat R, Galli F, Signore A, Hess S. PET radiopharmaceuticals for specific bacteria imaging: a systematic review. J Clin Med. 2019;8(2):197.

63. Zheng L, Ding X, Liu K, Feng S, Tang B, Li Q, et al. Molecular imaging of fibrosis using a novel collagen-binding peptide labelled with (99m)Tc on SPECT/CT. Amino Acids. 2017;49(1): 89-101.

64. Montesi SB, Desogere P, Fuchs BC, Caravan P. Molecular imaging of fibrosis: recent advances and future directions. J Clin Invest. 2019;129(1):24-33.

65. Désogère $\mathrm{P}$, Montesi SB, Caravan P. Molecular probes for imaging fibrosis and fibrogenesis. Chem Eur J. 2019;25(5):1128-41.

66. Désogère P, Tapias LF, Hariri LP, Rotile NJ, Rietz TA, Probst $\mathrm{CK}$, et al. Type I collagen-targeted PET probe for pulmonary fibrosis detection and staging in preclinical models. Sci Transl Med. 2017;9(384):eaaf4696. 
67. Szyszko TA, Yip C, Szlosarek P, Goh V, Cook GJR. The role of new PET tracers for lung cancer. Lung cancer (Amsterdam, Netherlands). 2016;94:7-14.

68. Maffione AM, Grassetto G, Rampin L, Chondrogiannis S, Marzola MC, Ambrosini V, et al. Molecular imaging of pulmonary nodules. AJR Am J Roentgenol. 2014;202(3):W217-23.

69. Zannetti A, Iommelli F, Speranza A, Salvatore M, Del Vecchio S. 3'-deoxy-3'-18F-fluorothymidine PET/CT to guide therapy with epidermal growth factor receptor antagonists and Bcl-xL inhibitors in non-small cell lung cancer. Journal of nuclear medicine : official publication, Society of Nuclear Medicine. 2012;53(3): 443-50.

70. Memon AA, Weber B, Winterdahl M, Jakobsen S, Meldgaard P, Madsen $\mathrm{HH}$, et al. PET imaging of patients with non-small cell lung cancer employing an EGF receptor targeting drug as tracer. Br J Cancer. 2011;105(12):1850-5.

71. van de Donk PP, Kist de Ruijter L, Lub-de Hooge MN, Brouwers $\mathrm{AH}$, van der Wekken AJ, Oosting SF, et al. Molecular imaging biomarkers for immune checkpoint inhibitor therapy. Theranostics. 2020;10(4):1708-18.

72. Niemeijer AN, Leung D, Huisman MC, Bahce I, Hoekstra OS, van Dongen G, et al. Whole body PD-1 and PD-L1 positron emission tomography in patients with non-small-cell lung cancer. Nat Commun. 2018;9(1):4664.

73. Greenspan BS. Role of PET/CT for precision medicine in lung cancer: perspective of the Society of Nuclear Medicine and Molecular Imaging. Translational lung cancer research. 2017;6(6):617-20.

74. Modlin IM, Lye KD, Kidd M. A 5-decade analysis of 13,715 carcinoid tumors. Cancer: Interdisciplinary International Journal of the American Cancer Society. 2003;97(4):934-59.

75. Baxi AJ, Chintapalli K, Katkar A, Restrepo CS, Betancourt SL, Sunnapwar A. Multimodality imaging findings in carcinoid tumors: a head-to-toe spectrum. RadioGraphics. 2017;37(2):51636.

76. Lococo F, Stefani A, Treglia G. Is fludeoxyglucosefluorodeoxyglucose-positron emission tomography/computed tomography ((18)F-FDG-PET/CT) really useless in staging pulmonary carcinoid tumors and in discriminating histological subtypes? Controversial points and future perspectives. Ann Thorac Med. 2015;10(3):217-8.

77. Jiang Y, Hou G, Cheng W. The utility of $18 \mathrm{~F}-\mathrm{FDG}$ and $68 \mathrm{Ga}-$ DOTA-peptide PET/CT in the evaluation of primary pulmonary carcinoid: a systematic review and meta-analysis. Medicine. 2019;98(10):e14769-e.

78. Deroose CM, Hindie E, Kebebew E, Goichot B, Pacak K, Taieb $\mathrm{D}$, et al. Molecular imaging of gastroenteropancreatic neuroendocrine tumors: current status and future directions. Journal of nuclear medicine : official publication, Society of Nuclear Medicine. 2016;57(12):1949-56

79. Chong S, Lee KS, Chung MJ, Han J, Kwon OJ, Kim TS. Neuroendocrine tumors of the lung: clinical, pathologic, and imaging findings. Radiographics. 2006;26(1):41-57.

80. Yankeelov TE, Peterson TE, Abramson RG, Izquierdo-Garcia D, Arlinghaus LR, Li X, et al. Simultaneous PET-MRI in oncology: a solution looking for a problem? Magn Reson Imaging. 2012;30(9):1342-56.

81. Chen DL, Kinahan PE. Multimodality molecular imaging of the lung. Journal of magnetic resonance imaging : JMRI. 2010;32(6): 1409-20.

82. Raad RA, Friedman KP, Heacock L, Ponzo F, Melsaether A, Chandarana $\mathrm{H}$. Outcome of small lung nodules missed on hybrid PET/MRI in patients with primary malignancy. J Magn Reson Imaging. 2016;43(2):504-11.

83. Schwenzer NF, Seith F, Gatidis S, Brendle C, Schmidt H, Pfannenberg CA, et al. Diagnosing lung nodules on oncologic
MR/PET imaging: comparison of fast T1-weighted sequences and influence of image acquisition in inspiration and expiration breath-hold. Korean J Radiol. 2016;17(5):684-94.

84. Fernandez-Perez G, Sanchez-Escribano R, Garcia-Vicente AM, Luna-Alcala A, Ceballos-Viro J, Delgado-Bolton RC, et al. SEOM-SERAM-SEMNIM guidelines on the use of functional and molecular imaging techniques in advanced non-small-cell lung cancer. Clin Transl Oncol. 2018;20(7):837-52.

85. Schaarschmidt BM, Grueneisen J, Metzenmacher M, Gomez B, Gauler T, Roesel C, et al. Thoracic staging with (18)F-FDG PET/ MR in non-small cell lung cancer-does it change therapeutic decisions in comparison to (18)F-FDG PET/CT? Eur Radiol. 2017;27(2):681-8.

86. Treglia G, Sadeghi R, Annunziata S, Lococo F, Cafarotti S, Bertagna F, et al. Diagnostic accuracy of 18F-FDG-PET and $\mathrm{PET} / \mathrm{CT}$ in the differential diagnosis between malignant and benign pleural lesions: a systematic review and meta-analysis. Acad Radiol. 2014;21(1):11-20.

87. Brun C, Gay P, Cottier M, Karpathiou G, Patoir A, Tiffet O, et al. Comparison of cytology, chest computed and positron emission tomography findings in malignant pleural effusion from lung cancer. Journal of thoracic disease. 2018;10(12):6903-11.

88. Porcel JM, Hernandez P, Martinez-Alonso M, Bielsa S, Salud A. Accuracy of fluorodeoxyglucose-PET imaging for differentiating benign from malignant pleural effusions: a meta-analysis. Chest. 2015;147(2):502-12.

89. Yildirim H, Metintas M, Entok E, Ak G, Ak I, Dundar E, et al. Clinical value of fluorodeoxyglucose-positron emission tomography/computed tomography in differentiation of malignant mesothelioma from asbestos-related benign pleural disease: an observational pilot study. J Thorac Oncol. 2009;4(12):1480-4.

90. Sun Y, Yu H, Ma J, Lu P. The role of 18F-FDG PET/CT integrated imaging in distinguishing malignant from benign pleural effusion. PLoS One. 2016;11(8):e0161764.

91. de Fonseka D, Underwood W, Stadon L, Rahman N, Edey A, Rogers C, et al. Randomised controlled trial to compare the diagnostic yield of positron emission tomography CT (PET-CT) TARGETed pleural biopsy versus CT-guided pleural biopsy in suspected pleural malignancy (TARGET trial). BMJ Open Respir Res. 2018;5(1):e000270.

92. Holcman K, Szot W, Rubis P, Lesniak-Sobelga A, Hlawaty M, Wisniowska-Smialek S, et al. 99mTc-HMPAO-labeled leukocyte SPECT/CT and transthoracic echocardiography diagnostic value in infective endocarditis. The international journal of cardiovascular imaging. 2019;35(4):749-58.

93. Hyafil F, Rouzet F, Lepage L, Benali K, Raffoul R, Duval X, et al. Role of radiolabelled leucocyte scintigraphy in patients with a suspicion of prosthetic valve endocarditis and inconclusive echocardiography. Eur Heart J Cardiovasc Imaging. 2013;14(6):58694.

94. Rouzet F, Chequer R, Benali K, Lepage L, Ghodbane W, Duval $\mathrm{X}$, et al. Respective performance of $18 \mathrm{~F}-\mathrm{FDG}$ PET and radiolabeled leukocyte scintigraphy for the diagnosis of prosthetic valve endocarditis. Journal of nuclear medicine : official publication, Society of Nuclear Medicine. 2014;55(12):1980-5.

95. Chen W, Dilsizian V. FDG PET/CT for the diagnosis and management of infective endocarditis: expert consensus vs evidencebased practice. J Nucl Cardiol. 2019;26(1):313-5.

96. Fiorani P, Speziale F, Rizzo L, De Santis F, Massimi GJ, Taurino $\mathrm{M}$, et al. Detection of aortic graft infection with leukocytes labeled with technetium 99m-hexametazime. J Vasc Surg. 1993, 17(1): 87-95 discussion -6 .

97. Erba PA, Leo G, Sollini M, Tascini C, Boni R, Berchiolli RN, et al. Radiolabelled leucocyte scintigraphy versus conventional radiological imaging for the management of late, low-grade 
vascular prosthesis infections. Eur J Nucl Med Mol Imaging. 2014;41(2):357-68.

98. Fujii T, Watanabe Y. Multidisciplinary treatment approach for prosthetic vascular graft infection in the thoracic aortic area. Ann Thorac Cardiovasc Surg. 2015;21(5):418-27.

99. Palestro CJ, Love C, Tronco GG, Tomas MB. Role of radionuclide imaging in the diagnosis of postoperative infection. RadioGraphics. 2000;20(6):1649-60.

100. Erba PA, Sollini M, Conti U, Bandera F, Tascini C, De Tommasi $\mathrm{SM}$, et al. Radiolabeled WBC scintigraphy in the diagnostic workup of patients with suspected device-related infections. JACC Cardiovasc Imaging. 2013;6(10):1075-86.

101. Habib G, Lancellotti P, Antunes MJ, Bongiorni MG, Casalta JP, Del Zotti F, et al. 2015 ESC guidelines for the management of infective endocarditis: the Task Force for the Management of Infective Endocarditis of the European Society of Cardiology (ESC). Endorsed by: European Association for Cardio-Thoracic Surgery (EACTS), the European Association of Nuclear Medicine (EANM). Eur Heart J. 2015;36(44):3075-128.

102. Hitzel A, Manrique A, Etienne M, Chastan M, Salles A, EdetSanson A, et al. $99 \mathrm{mTc}$ leukocyte SPECT/CT for diagnosis of left ventricular assist device (LVAD) infection. Journal of Nuclear Medicine. 2009;50(supplement 2):1343.

103. Litzler P-Y, Manrique A, Etienne M, Salles A, Edet-Sanson A, Vera P, et al. Leukocyte SPECT/CT for detecting infection of leftventricular-assist devices: preliminary results. J Nucl Med. 2010;51(7):1044-8.

104. Kim GE, Sung IY, Ko EJ, Choi KH, Kim JS. Comparison of videofluoroscopic swallowing study and radionuclide salivagram for aspiration pneumonia in children with swallowing difficulty. Ann Rehabil Med. 2018;42(1):52-8.

105. Jang DH, Choi KH, Kim DH, Lim CM, Kim JS. Comparison between the radionuclide salivagram and videofluoroscopic swallowing study methods for evaluating patients with aspiration pneumonia. Ann Nucl Med. 2013;27(3):247-52.

106. Park D, Woo SB, Lee DH, Yu KJ, Cho JY, Kim JM, et al. The correlation between clinical characteristics and radionuclide salivagram findings in patients with brain lesions: a preliminary study. Ann Rehabil Med. 2017;41(6):915-23.

107. Yang M, Covington MF, Nguyen BD, Johnson GB, Mesa RA, Roarke MC. (99m)Tc-sulfur colloid bone marrow Scintigraphy in diagnosis of diffuse pulmonary extramedullary hematopoiesis secondary to myelofibrosis. Journal of nuclear medicine technology. 2018;46(4):368-72.
108. Yammine JN, Yatim A, Barbari A. Radionuclide imaging in thoracic splenosis and a review of the literature. Clin Nucl Med. 2003;28(2):121-3.

109. Houshmand S, Salavati A, Hess S, Ravina M, Alavi A. The role of molecular imaging in diagnosis of deep vein thrombosis. American journal of nuclear medicine and molecular imaging. 2014;4(5):406-25.

110. Morris TA. SPECT imaging of pulmonary emboli with radiolabeled thrombus-specific imaging agents. Semin Nucl Med. 2010;40(6):474-9.

111. Dunzinger A, Hafner F, Schaffler G, Piswanger-Soelkner J-C, Brodmann M, Lipp RW. 99mTc-apcitide scintigraphy in patients with clinically suspected deep venous thrombosis and pulmonary embolism. Eur J Nucl Med Mol Imaging. 2008;35(11):2082-7.

112. Macfarlane D, Socrates A, Eisenberg P, Larcos G, Roach P, Gerometta $\mathrm{M}$, et al. Imaging of deep venous thrombosis in patients using a radiolabelled anti-D-dimer $\mathrm{Fab}^{\prime}$ fragment $(99 \mathrm{mTc}-\mathrm{DI}-$ DD3B6/22-80B3): results of a phase I trial. Eur J Nucl Med Mol Imaging. 2009;36(2):250-9.

113. Douketis JD, Ginsberg JS, Haley S, Julian J, Dwyer M, Levine M, et al. Accuracy and safety of (99m)Tc-labeled anti-D-dimer (DI80B3) Fab' fragments (ThromboView $®)$ in the diagnosis of deep vein thrombosis: a phase II study. Thromb Res. 2012;130(3):3819.

114. Ciesienski KL, Yang Y, Ay I, Chonde DB, Loving GS, Rietz TA, et al. Fibrin-targeted PET probes for the detection of thrombi. Mol Pharm. 2013;10(3):1100-10.

115. Langbein T, Weber WA, Eiber M. Future of theranostics: an outlook on precision oncology in nuclear medicine. Journal of nuclear medicine : official publication, Society of Nuclear Medicine. 2019;60(Suppl 2):13s-19s.

116. Bonniaud P, Burgy O, Garrido C. Heat shock protein-90 toward theranostics: a breath of fresh air in idiopathic pulmonary fibrosis. Eur Respir J. 2018;51(2):1702612.

117. Bellaye P-S, Shimbori C, Yanagihara T, Carlson DA, Hughes P, Upagupta C, et al. Synergistic role of HSP90 $\alpha$ and HSP90 $\beta$ to promote myofibroblast persistence in lung fibrosis. Eur Respir J. 2018;51(2):1700386.

Publisher's Note Springer Nature remains neutral with regard to jurisdictional claims in published maps and institutional affiliations. 